\title{
RESEARCH CAPABILITIES OF PUBLIC ELEMENTARY SCHOOL TEACHERS AND MANAGEMENT SUPPORT OF THE SCHOOLS DIVISION OF NUEVA VIZCAYA, PHILIPPINES
}

\author{
Irene B. Gonzales ${ }^{1 *}$, Demetria A. Corpuz ${ }^{2}$, Rhowel M. Dellosa ${ }^{3}$
}

${ }^{1 *}$ Principal, Department of Education, Division of Nueva Vizcaya, Philippines; ${ }^{2}$ Associate Professor, Nueva Vizcaya State University, Philippines; ${ }^{3}$ Dean, CEITE, Asia Technological School of Science and Arts, Philippines. Email: ${ }^{1 *}$ irene.gonzales008@deped.gov.ph, ${ }^{2}$ demetria_corpuz@yahoo.com, ${ }^{3}$ rhoweldellosa@ asiatech.edu.ph

Article History: Received on $24^{\text {th }}$ April 2020, Revised on $29^{\text {th }}$ June 2020, Published on $17^{\text {th }}$ July 2020

\section{Abstract}

Purpose of the study: This study determined the research capabilities of public elementary teachers in the Schools Division of Nueva Vizcaya and also to determine the management support extended to them in terms of research support and research environment condition.

Methodology: This study employed the descriptive-correlational method. The descriptive method described the characteristics of the respondents, the level of research capabilities and dissemination, and management research support factors. Two hundred eighteen respondents were drawn from the population. A Stratified random sampling method was used to determine samples per stratum. The researchers observed research ethics and protocols during the gathering process. Descriptive-Inferential statistics were used to interpret the data.

Main Findings: The study found out that respondents who attained higher educational attainment and attended national training have improved research skills and are more knowledgeable in the research process and dissemination. The respondents are moderately capable in their research capabilities and research dissemination. The level of research capabilities was significantly correlated with educational attainment and training. Research support was inadequate; a favourable research environment was provided.

Applications of this study: The findings of the study provide data to the Department of Education to know the factors affecting the research capabilities of public school teachers. The DepEd school heads can come up with a workable plan to enhance research capabilities and manage their resources, policies, time, space, and personnel for maximum effect.

Novelty/Originality of this study: The fast trend in instructional technology and innovative approaches and teaching pedagogies, knowledge, and skills in the research of all academic professionals is essential. Conducting research becomes now mandatory in the educational institutions in the Philippines; thus, needs continuous assessment to produce a community of teacher-researchers.

Keywords: Research Capabilities, Research Management Support, Research Skills, Research Dissemination.

\section{INTRODUCTION}

The educational research is recognized as the basis for reforms and policy development. It is a scientific investigation to find facts, solutions, and relationships to various phenomena. Through research, man gains social, economic, cultural, and political benefits Calderon \& Gonzales (1993). Scholars, graduate students, and professionals in the academic discipline are engaged in research for it greatly influenced or affected the operation of the school system (Zulueta \& Perez, 2010).

In the Philippines, the Higher Education has the primordial mandate to conduct research, while in basic education, research is simply secondary to the teaching tasks of teachers. The Department of Education (DepEd) has a strong drive to motivate teachers to conduct research. Several directives had been instituted by the DepEd to provide funding and improve research culture (DepEd Order (DO) No. 24 s. 2010; DO No. 43 s. 2015). The DO No 4 s. of 2015 provides guidelines in the utilization of the Basic Education Research Fund. Also, DepEd Order No. 16, s. 2017 provides Research Management Guidelines (RMG). Further, the policy mentions research as one of the critical performance indicators in the new Result-based Performance Management System (RPMS), hence, it becomes a part of the teacher's tasks. The DO No. 39 s. 2016 promulgates the Basic Education Research Agenda (BERA), which sets different research priorities. Despite these mandates, teachers still face challenges in doing research.

Being catalysts, teachers, and school administrators are involved in classroom situations. They witness and experience problems and classroom situations which can be the topics for action research. In research, they would be able to come up with valid scientific results that can resolve problems and improve teaching and enhance students' learning (Igwe, 2015).

The role and influence of school administrators are vital in school management; they provide direction, plan, and implement various strategies to improve the quality of learning (Al-Jabari 2014; Al-Rasyid, 2020). Since research had been a common concern in educational institutions, administrators have to face the challenge to initiate the conduct of action research. The Administrators and teachers work in convergence to effect change in the school as well as the

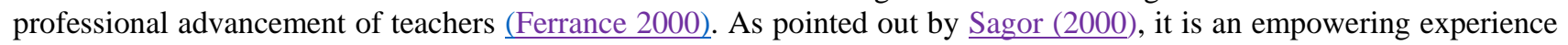


for leaders who engage in action research. As Brewer, Brewer \& Hilton (2000) emphasized that the provision of adequate support and the needs of researchers to undertake research studies is one of the most essential factors in promoting research activities.

Moreover, studies revealed challenges that hamper them to conduct research. Lack of financial support, insufficient research knowledge, and skills, heavy teaching loads are some of the obstacles (Ulla 2017; Ellis \& Loughland 2016; Vasquez, 2017). Similar findings emerged in the study of Zhou (2012). The teachers were not confident in their acquired research skills and did not have a clear understanding of research. Lack of training would affect the interest, confidence, and motivation of teachers. Also, in the study of Fuentes (2017), teacher education students need inputs on how to produce quality research papers. The students need further training in research. In the study of Yuan \& Lee (2014), Chinese teachers are required to take a doctorate that manifests their extensive research training and experiences. They are also encouraged to publish research outputs; however, sufficient research support is scarce.

According to Al-Jabari (2014) \& Honcock (1995), researchers have shown previously that research productivity depends heavily on the time spent on research-related activities. In the private higher institutions, research productivity posts a great challenge. The support from the organization greatly influences research outputs. The high demands for research outputs, availability of research assistants, rewards and incentives, research skills and research policy affect performance. (McGill \& Settle 2012; Azad and Seyyed 2007; Cloete et al. 2011; Enero 2000)

Further, in the study of Wodarsky (2001), teaching load has effects on research productivity that occur across the different fields and clusters of departmental areas. Furthermore, the study of Santo, Engstrom, Reetz, Schweinle, and Reed (2009) conclude that insufficient time and heavy teaching load affect research productivity.

Teachers' and school heads' capabilities to do action research are very essential in school improvement, curriculum review, and professional growth. It is a big challenge for them to come up with quality research and increased research productivity. Hence, technical assistance, working arrangements, a culture of research, and motivational support are some factors that would encourage teachers to undertake research. It is for these reasons that the researchers focused this study on assessing the level of management support extended and level of research capabilities of public elementary school teachers in the northern districts of the Schools Division of Nueva Vizcaya, Philippines.

\section{Objectives of the Study}

This study analyzed the research capabilities of public elementary school teachers and management support of the schools division of Nueva Vizcaya in the Philippines. Specifically, it aimed to

(1) Determine the level of the respondents' research capabilities in terms of research skills and Process and research dissemination;

(2) Determine the level of the management support received by the respondents in terms of research support and research environment;

(3) Establish a significant relationship between the profile variables and research capabilities;

(4) Establish the significant relationship between profile variables and management factors, and

(5) Establish significant relationships between the levels of research capabilities and management support.

\section{LITERATURE REVIEW}

There were several types of research done on factors affecting teachers' research support, effective research environment, and research capabilities. Higher education institutions (HEIs) have to respond to technological advancement as part of their prime mandate. Nowadays, economic and sustainable development is dependent on academic research. Research endeavour finds solutions and improves intellectual skills and knowledge (Manongsong \& Panopio, 2018). The provision of adequate research support as one of the essential factors in promoting research activity is wanting. Funding, ICT equipment, books/references from libraries, and the most common is verbal encouragement from superiors are research supports that a researcher needs to achieve excellent performance in research studies (Brewer, Brewer, \& Hilton 2000). On the other hand, researchers have also shown that research productivity depends heavily on how much time one spends on research-related activities Teaching load has differential effects on research productivity that occur across the different fields and clusters of departmental areas (Hancock 1995; Wodarski 2001). This was affirmed by (Morales 2016; Kutlay 2012). Tight teaching schedule and teaching overload demotivated teachers to conduct research.

Previous studies have shown that motivational factors such as financial rewards, promotion, and performance enhance research skills and Process, and research dissemination are equally important. The financial reward could be a symbol of success, a reinforcer and motivator, a reflection of one's performance, and a source of reduced anxiety. Promotion leads to a higher salary, higher social status, better work conditions, more administrative power, more respect from colleagues and students, and other fringe benefits (Lai 1990; Rowley, 1996). The provision of adequate research support is one of the most essential factors in promoting research activity. Funding, ICT equipment, books/references from libraries, and the most common is verbal encouragement from superiors are research supports that a researcher needs to achieve 
excellent performance in research studies (Brewer, Brewer \& Hilton 2000). Ferrance (2000) posited the role of administrators has a great influence on school improvement and teacher's skills enhancement. Administrators help teachers by working collaboratively for their professional development.

Additionally, earlier studies show that academic staff needs to be research competent and productive. The declining research skills, knowledge, and productivity of teachers hamper the development of academic education. The study of Wong (2019; Vogrinc \& Zuljan 2009; Hong \& Lawrence 2011) emphasized that there is a need to strengthen institutional support, improve research attitude and skills for better research productivity.

Witchian et al. (2009) also found a direct link between research productivity and the characteristics of an institution that helps enhance research competence and various attributes of an institution that helps enhance research capability. Once teachers' research capability establishes, research productivity increases. Formeloza \& Pateña (2013) determined the level of competency in writing a research paper, level of satisfaction on the facilities/resources provided by the institution. The results revealed that both respondents were moderately competent in terms of technical aspects and doing significant parts of the research paper as well. On the other hand, they are satisfied with the facilities provided by the university. Lovat, Davies, and Plotnikoff (1995) recognized that integrating research in the teacher education curriculum has a positive effect on teachers. The study of Papanastatasiou (2005) emphasizes the development of positive attitudes towards research to enhance teachers' capability and increase awareness. Understanding of these attitudes is necessary to help instructors facilitate the learning of research for their students. The usefulness of research, anxiety, affect indicating positive feelings about research, life relevancy of research to the students' daily lives, and difficulty of research are factors that were considered thus, reduces negative views on the research. In 2016, Bell focused a study on the challenges faced in developing research competencies. The study determined that the centred approach has a significant relationship on learner's performance in comparison with the traditional semester approach, and it helped in developing the research competencies within learners.

Hypotheses of the Study: based on the above discussion, in this study it was assumed that

(1) There are no significant relationship between profile variables and research capabilities;

(2) There are no significant relationship between profile variables and management factors; and

(3) There are no significant relationships between the levels of research capabilities and management support.

\section{METHODOLOGY}

This study employed the descriptive-correlational method. The descriptive method described the characteristics of the teacher-respondents, the level of management research support factors, and their research capabilities along with research skills, process, and dissemination. The correlational method was employed to establish the relationships between and among variables. The respondents of this study were the public elementary school teachers of the different schools in the Northern District, Schools Division of Nueva Vizcaya, Philippines. All of the teacher-respondents occupy permanent positions. Due to different geographical locations, the researchers used multi-stage sampling. The total respondents were determined and computed with the use of Slovins' formula with 0.05 margin of error. Out of 480 permanent teachers, there were 218 respondents drawn through systematic random sampling.

The management support and research capabilities of public elementary teachers were gathered through a structured researcher-made questionnaire which underwent content validation. The researchers personally administered and retrieved the questionnaires to all the target areas until the desired number of respondents in each district was obtained. All the gathered data were treated properly; variables were coded for statistical data analysis. Descriptive statistics such as frequency counts, percentages, means, and standard deviations were used to profile the respondents, as well as to determine the level of management support and research capabilities of the elementary teachers. Product Moment Correlation, Spearman's rho, and Point Biserial Correlation Coefficients were used to establish the relationships between and among the profile variables, management support, and research capabilities of the respondents.

\section{RESULTS AND DISCUSSION}

\section{Profile of the Respondents}

The study respondents were within the average age of 42.69 years. This data denotes that the respondents belonged to the middle-aged group. They are mostly married $(88.5 \%)$ females (90\%) which is reflective of the prevailing scenario in the Department of Education. The majority of the respondents were holders of baccalaureate degrees, while $20 \%$ had finished their advanced education. Most of the respondents belonged to the Teacher III (67.4\%) positions. Also, more than half of the respondents attended research seminars or training in the District, Division, and School levels (74.3\%). Only a few attended research seminars or training organized at the Regional, National, and International levels. As to research involvement, the 218 respondents finished only a few researches. The majority of the respondents accomplished one research work, and very notably, there were 3 or $1.4 \%$ of the respondents worked in pairs. 


\section{Level of Respondents' Research Capabilities}

\section{Research Skills and Process}

Table 1: Summary table of the level of management factors in terms of research skills and process and research dissemination

\begin{tabular}{llll}
\hline Indicators & Mean & Standard Deviation & Qualitative Description \\
\hline Research Skills and Process & 3.33 & 0.85 & Moderately capable \\
\hline Research Dissemination & 3.14 & 1.00 & Moderately capable \\
\hline Grand Mean & $\mathbf{3 . 2 4}$ & $\mathbf{0 . 9 2}$ & Moderately capable \\
\hline
\end{tabular}

Table 1 shows the summary level of research capabilities in terms of research skills and Process and research dissemination. Generally, the grand mean of 3.24 indicated that teachers were moderately capable in terms of research skills and process (3.33) and Research dissemination (3.14). The result implies that the research skills of teachers are moderate, indicating that they can research with minimal assistance from a research mentor. However, in research dissemination, teachers still need to be capacitated to produce quality research.

On Research Skills and Process: The result confirmed that teachers were highly capable of identifying relevant classroom /school-based problem/s and crafting research problem/s (research title) together with specific questions. Additionally, teachers are moderately capable of developing a research framework that will serve as a guide in the research study, preparing the summary of the study, drawing conclusions and identifying doable research recommendations, organizing related studies and literature based on the identified research problem. Findings further show that the respondents are also moderately capable of determining relevant theories and concepts relative to the framework of the research study; developing a new strategy or approach to address the identified research problem; using different sampling procedures appropriate for the study. Further, the respondents are moderately capable of analyzing, organizing, and interpreting qualitative and quantitative data; preparing correct prescribed bibliographic formats like APA style of referencing; developing valid and reliable research instruments and tools, and identifying appropriate statistical tools in analyzing the gathered data. Findings of the study reinforce the study of Salom (2013) who found out that teachers lacked the necessary skills, such as constructing data-gathering instruments, doing statistical treatments, and interpreting findings. Likewise, in the study conducted by Corpuz (2012) on the Effectiveness and Training Needs of Tertiary Faculty, respondents were in great need of research training that would enhance their research skills which consequently will redound to the improvement of classroom instruction. As Stewart (2013) mentioned, lack of knowledge and time constraints are among the problems of classroom teachers.

On Research Dissemination: The result revealed that the respondents' research capabilities in terms of research dissemination were moderately capable in presenting research output in various forms, and publishing of research output in the research journal. Further, the respondents are moderately capable of incorporating research output in the production of instructional materials, modules, etc., and disseminating research output through different media and fora. Although the respondents rated themselves moderately capable, the teachers still needed to be capacitated with the research dissemination to produce quality research.

These findings run moderately better than the scenario established by Budi (2010) which showed that the extent of faculty researches conducted, dissemination of research findings, and use of research findings were limited while the faculty participation as reviewers of research was minimal. The study further pointed out that research-based factors, research-related factors, and organization-related factors moderately hindered the involvement of the faculty along with the conduct of research, dissemination of research, review of research, and use of research. Lacanaria (2008), concluded that the extent of faculty participation in research activities was lower than the expectations of the university and the mandates of CHED. The faculty participation in the review of research was much constrained by factors related to the nature of research capability, attitude, and the research climate in the work setting limited faculty participation.

\section{Level of the Respondents' Management Support Factors}

Table 2: Summary table of the level of management factors in terms of research support and research environment

\begin{tabular}{llll}
\hline Indicators & Mean & Standard Deviation & Qualitative Description \\
\hline Research Support & 3.34 & 1.14 & Moderately Provided \\
\hline Research environment & 3.25 & 1.09 & Moderately Provided \\
\hline Grand Mean & $\mathbf{3 . 2 9}$ & $\mathbf{1 . 1 1}$ & Moderately Provided \\
\hline
\end{tabular}

Table 2 shows the overall level of management factors in terms of research support (3.34) and the research environment (3.25). Generally, the grand mean of 3.29 indicated that teachers were moderately provided in terms of research support to enhance the research capabilities of elementary school teachers, while the research environment was just enough for them.

Research Support: The results indicated that the teachers were provided with enough opportunities for research training/seminars at local, national, and international levels. Technical research assistance was given by the immediate 
supervisor or by an expert teacher. There were available research grants provided by the DepEd or by other funding agencies and good instructional leadership in the conduct of research in the school is evident. Further, the following were moderately provided: incentives (monetary reward, scholarship, etc.) to teachers with research output, availability of research publication/journal/online. The least ratings were given to provision for supplies and other materials to researchers. As pointed out in the study of Corpuz (2012), technologies are an indispensable state of the art. The use of computers and effective ICT integration is beneficial in the teaching-learning Process and research endeavours. Technology can change and improve the quality of learning outcomes if it is designed to support research knowledge acquisition in a research centred environment.

Research Environment: The respondents rated all indicators of the management support factors in terms of the research environment as moderately provided. They are as follows: there are personnel in-charge to manage research proposals and outputs of research in the school, district and division levels; there is an existing school-based policy on research; there are personnel in-charge in monitoring the conduct of research work in the school, district and division levels; fostering research culture in the school, district, and division; and there is a clear-cut procedure in the conduct of research in the school. Guidelines on the use of available funds for research got the lowest rating.

\section{Relationship between Profile Variables and Research Capabilities}

Table 3: Summary table for the Correlation matrix on the relationship between the profile variables and research capabilities

\begin{tabular}{lllllll}
\hline \multirow{2}{*}{ Profile Variables } & \multicolumn{2}{l}{$\begin{array}{l}\text { Research Skills } \\
\text { and Process }\end{array}$} & \multicolumn{2}{l}{$\begin{array}{l}\text { Research } \\
\text { Dissemination }\end{array}$} & \multicolumn{2}{l}{$\begin{array}{l}\text { Overall } \\
\text { Research Capabilities }\end{array}$} \\
\cline { 2 - 8 } & $\mathrm{R}$ & sig & $\mathrm{R}$ & sig & $\mathrm{r}$ & sig \\
\hline Highest Educational Attainment & $\mathbf{0 . 2 5 4}^{* *}$ & $<.001$ & $\mathbf{. 1 5 1}^{*}$ & 0.027 & $\mathbf{. 2 1 0 *}$ & 0.002 \\
\hline Training, national level & $\mathbf{0 . 4 5 9}^{*}$ & 0.042 & 0.362 & 0.116 & $\mathbf{. 4 4 5}^{*}$ & 0.049 \\
\hline Training, international level & $\mathbf{0 . 4 3 6}^{*}$ & 0.023 & 0.173 & 0.387 & 0.305 & 0.122 \\
\hline
\end{tabular}

Research Skills and Process: The level of research skills and process of the respondents positively and significantly correlated with highest educational attainment $(\mathrm{r}=0.254 ; \mathrm{p}=\langle 0.01)$, attendance to national training $(\mathrm{r}=0.459 ; \mathrm{p}=$ $0.042)$, and attendance to international trainings $(r=0.436 ; p=0.023)$, which were enough evidences to reject the null hypothesis. The positive correlation coefficients denoting the relationships between the variables inferred direct association, or when the other variable increased in value, it would also enhance the value of the other variable.

The result further indicates that on educational attainment, the higher the educational qualification of the respondents, the higher would also be their research skills. Attaining higher education, above a bachelor's degree, would equip the respondents with greater research skills. Corpuz (2020) noted that teachers' knowledge in the learning management system enables communication and sharing of resources. Likewise, the attendance of respondents' teachers to national and international training would give them the chance to acquire advanced skills in research. The direct relationships between the variables also inferred that more exposures to national and international training, the higher would give higher research skills.

The current study finds support to Salom's (2013) \&Tamban's (2020) findings that teachers were moderately capable in terms of technical writing in research and that the highest educational attainment shows a significant relationship to research capability. Further, Abarro (2016) noted that the research capabilities of public elementary school teachers affirmed the research seminars/training attended and negated the highest educational attainment. The RA 10912 known as Continuing Professional Development Act of 2016, requires all professionals to attend to continuing professional education whether seminars, training, or professional advancement to enhance their competence thereby meeting national and global standards.

Research Dissemination: The research capability of the respondents measured in terms of their knowledge of research dissemination correlated significantly only with the profile variable's highest educational attainment $(\mathrm{r}=0.151 ; \mathrm{p}=$ 0.027). The positive significant correlation coefficient indicated a direct relationship. The result implies again that the higher the educational attainment of the respondents, the higher would also be their research skills. It further inferred that the respondents with higher educational achievements also had higher research capabilities in terms of their knowledge in the research process and dissemination of research results in various media.

Overall Research Capabilities: The overall research capabilities of the respondents positively and significantly correlated with highest educational attainment $(\mathrm{r}=0.210 ; \mathrm{p}=0.001)$, attendance to national training $(\mathrm{r}=0.459 ; \mathrm{p}=$ 0.042). The result indicates that respondents who had higher educational attainment or were exposed more to national training also had higher research capabilities such as research skills and Process and knowledge in research dissemination. 
On the other hand, the profile variables age, sex, civil status, permanent position, and even research involvement were not significantly correlated with the research capabilities of elementary school teachers such as research skills and Process and knowledge in research dissemination.

Hypothesis 1 predicts that there are no significant relationships between the profile variables and research capabilities; Based on the results shown in the correlation matrix on the relationship between the profile variables and research capabilities results, hypothesis number 1 was not supported.

\section{Relationship between Profile Variables and Level of Management Factors}

Table 4: Summary table of the correlation matrix on the relationship between the profile variables and level of management factors

\begin{tabular}{|c|c|c|c|c|c|c|}
\hline \multirow{2}{*}{ Profile Variables } & \multicolumn{2}{|c|}{ Research Support } & \multicolumn{2}{|c|}{$\begin{array}{l}\text { Research } \\
\text { Environment }\end{array}$} & \multirow{2}{*}{$\begin{array}{l}\begin{array}{l}\text { Overall } \\
\text { Support }\end{array} \\
\mathrm{R}\end{array}$} & \multirow{2}{*}{$\begin{array}{l}\text { Management } \\
\mathrm{Sig}\end{array}$} \\
\hline & $\mathrm{r}$ & Sig & $\mathrm{R}$ & $\mathrm{Sig}$ & & \\
\hline $\begin{array}{l}\text { Highest } \\
\text { Attainment }\end{array}$ & 0.117 & 0.087 & $\mathbf{0 . 1 5 8}^{*}$ & 0.021 & $\mathbf{0 . 1 5 3}^{*}$ & 0.025 \\
\hline Training, district level & $-0.190^{*}$ & 0.016 & -0.126 & 0.113 & $-0.170^{*}$ & 0.032 \\
\hline Training, international level & -0.290 & 0.143 & $-0.389^{*}$ & 0.045 & -0.362 & 0.064 \\
\hline Total number of training & $-0.149^{*}$ & 0.030 & -0.053 & 0.439 & -0.108 & 0.116 \\
\hline Total research involvement & $-0.143^{*}$ & 0.036 & -0.034 & 0.619 & -0.094 & 0.170 \\
\hline
\end{tabular}

The study found out that the level of research support provided by the school significantly correlated with the following profile variables: number of trainings attended in the district level $(r=-0.190 ; p=0.016)$, total number of trainings attended $(r=-0.149 ; p=0.030)$, and the total number of research involvement $(r=-0.143 ; p=0.036)$.

The negative correlation coefficients indicating the relationships between the training attended and the level of research support provided by the school implies that respondents who have more district training as well as those who have attended more number of training, from school level to international level training, perceived that the institution where they belong have a low level of research support by the management of their school. Moreover, they feel that the school or the institution where they belong has inadequate provisions to support research works by their teachers.

Likewise, negative correlation coefficient denoting the relationships between the total number of research involvement and the level of research support provided by the school infers that those who have been involved in research work whether individual work, group works or in pair, also perceived that the institution where they belong have inadequate research support by the management of their school. They also feel that the institutions where they work offer inadequate provisions to support the research activities of their teachers.

Research Environment: The management support in terms of provision of friendly research environment significantly correlated with the following: highest educational attainment $(\mathrm{r}=0.158 ; \mathrm{p}=0.021)$, and the number of international training attended $(\mathrm{r}=-0.389 ; \mathrm{p}=0.045)$. The positive correlation between the profile variable and the management support in terms of provision conducive research environment implies that respondents who have higher educational attainment perceive that the school or the institution where they belong have adequate provisions for a friendly research environment to their teachers. The higher their educational attainment, the more they perceive that an amiable research environment exists in their school, and vice versa, or the lower the educational attainment, the more they observe that a friendly research environment does not exist in their school.

Contrariwise, the negative relationship between the number of international training attended and the provisions for a friendly research environment indicate deductive relationships between the two variables. The result infers that those who have attended more international training and might have observed facilities in various institutions realized that the research environments existing in their schools are still inadequate in terms of research support by their faculty. Further, the more they have attended international training, the more they realized that the research environments existing in their schools are inadequate.

\section{Overall Management Support}

The study found out that the overall level of management support provided by the school significantly correlated with the following profile variables: highest educational attainment level $(r=0.153 ; p=0.025)$, and the number of training attended in the district level $(\mathrm{r}=-0.170 ; \mathrm{p}=0.032)$. The positive correlation between highest educational attainment and the overall level of management support provided by the school implies that respondents who have higher educational attainment perceived that the school or the institution where they belong have adequate management support accorded to their teachers. However, the negative relationship between the number of training attended at the district level and the overall level of management support provided by the school indicates that those who have attended more district-level training observed that the school or the institution where they belong have inadequate management support accorded to 
their teachers. The result of the present study runs better than the result of (Biruk (2013). There was limited training, seminar, and workshop regarding research and that management must allocate adequate budget and provide training, seminars, and workshops to increase the number of teachers who would be involved in the research.

Hypothesis 2 predicts that there are no significant relationships between the profile variables and management support factors. As shown from the results in the correlation matrix on the relationship between the profile variables and management support, hypothesis number 2 was not supported.

\section{Relationships between the Levels of Management Factors and Research Capabilities}

Table 5: Summary table of the correlation matrix on the relationships between and among the level of motivational factors, management factors, and research capabilities

\begin{tabular}{lllllll}
\hline \multirow{2}{*}{ Management Factors } & \multicolumn{2}{l}{$\begin{array}{l}\text { Research } \\
\text { Process }\end{array}$} & Skills and & \multicolumn{2}{l}{$\begin{array}{l}\text { Research } \\
\text { Dissemination }\end{array}$} & \multicolumn{2}{l}{$\begin{array}{l}\text { Overall } \\
\text { Capabilities }\end{array}$} & Research \\
\cline { 2 - 8 } & $\mathrm{r}$ & $\mathrm{sig}$ & $\mathrm{r}$ & $\mathrm{sig}$ & $\mathrm{R}$ & $\mathrm{sig}$ \\
\hline Research Support & $0.525^{* *}$ & $<0.001$ & $0.488^{* *}$ & $<0.001$ & $0.538^{* *}$ & $<0.001$ \\
\hline Research Environment & $0.590^{* *}$ & $<0.001$ & $0.585^{* *}$ & $<0.001$ & $0.626^{* *}$ & $<0.001$ \\
\hline Overall Management Support & $0.617^{* *}$ & $<0.001$ & $0.595^{* *}$ & $<0.001$ & $0.646^{* *}$ & $<0.001$ \\
\hline
\end{tabular}

The extent of management support accorded by the school to the respondents such as research support, favourable research environment and the overall management support significantly correlated with the research capabilities of the respondents especially in developing and implementing research works, following the appropriate Process in conducting research and dissemination of research results in various forms of media, and their overall research capabilities. It further means that the greater the extent of motivational factors accorded to the respondents, and the more adequate the management support is given to the researchers, the higher would also be the research capabilities of the respondents.

Hypothesis 3 predicts that there are no significant relationships between the levels of research capabilities and management support. As shown from the results in the correlation matrix on the relationship between the profile variables and management support, hypothesis number 3 was not supported.

The present findings of this study support Ulla, Barrera, \& Acompanado (2017) that job promotion is a strong motivating factor to research teachers. However, their interest to do research is still conditional, provided that their needs would be met and given. There should be provision and opportunity for attendance and participation in various research training to develop their research skills.

\section{CONCLUSIONS}

The public elementary teachers were moderately capable in their research skills and research dissemination. The respondents considered support for research by management and the environment being conducive to research as moderately provided. Moreover, Elementary school teachers who had higher educational attainment perceived that the school where they belonged had accorded them with an environment conducive to conducting research. At the same time, those who attended district level training observed that the school or the institution where they belong still needed to enhance the capability of teachers to do quality research. Elementary school teachers who attained higher educational attainment and attended national training also had improved research and process skills and more knowledgeable in research dissemination.

The officials of the Department of Education may provide public elementary school teachers with the needed motivation to research by providing them monetary and non-monetary incentives and adequate management support to polish their research skills and capability in disseminating and publishing the results in different media. Further, the department may intensify the conduct of mentoring and training to produce quality research and craft a functional teachers' development plan for advanced education for broadening their knowledge and research skills.

\section{LIMITATION AND STUDY FORWARD}

The study was confined only in one school division in the Department of Education, the Philippines delimited with differing geographical distance and setting. For further study, a larger sample may be considered in a nationwide scope to elicit a general concept of the teachers' research skills. Researchers may replicate the study to continually evaluate the progress of teachers' research skills. Continuous evaluation is a vital mechanism for the enhancement of the teaching and learning process and curriculum enhancement.

\section{CO-AUTHOR CONTRIBUTION}

The co-authors had equal participation in the conceptualization until the publication of the research paper. Further, the second co-author facilitated the outsourcing of funding support, while the third author, work extensively on the journal publication. Research collaboration is evident. 


\section{REFERENCES}

1. Abarro, J. \& Marino, W. (2016). Research Capabilities of Public Secondary and Elementary School Teachers in the Division of Antipolo City. Australian Journal of Teacher Education, 42(11). Retrieved from http://ro.ecu.edu.au/ajte/vol42/iss11/4

2. Al-Jabari, B. (2014). The Influence of Effective Leadership on School Climate. https://doi.org/10.2139/ssrn.2541105

3. Al Rasyid, H. et al. (2020). Effect of Effectiveness of Principal leadership and Implementation of Teacher Quality Improvement Strategies on School Quality and Quality of Graduates in Junior High School Tourism Hospitality accommodation West Jave-Indonesia. Journal of Critical Reviews 7(4). https://doi.org/10.31838/jcr.07.04.11

4. Azad, A.N. \& Seyyed, F.J. (2007). Factors influencing faculty research productivity. Evidence AACSB accredited schools in the GCC Countries. Journal of International Business Research, 6(1), 91.

5. Biruk, E. (2013). The practice and challenges in conducting action research: The case of Sululta Secondary School. Institute of Educational Research. Addis Ababa University, Ethiopia.

6. Brewer, P., Brewer, V., \& Hilton, C. (1990). Promoting research productivity in colleges of business. Journal of Education for Business, 66(1), 52-56. https://doi.org/10.1080/08832323.1990.10117453

7. Budi Prasetyo A.P. (2010). Learning Paradigm of Biology Teaching, Educational Background, School Culture, Perception, Attitude, Intrinsic Motivation, Metacognitive Awareness. Retrieved on September 19, 2012 from: pasca.um.ac.id/.../5-collection-abstract-BIO-S3-2.

8. Calderon, J. F. \& Gonzales, E.C. (1993). Methods of Research and Thesis Writing. Manila: National Book Store.

9. CHED Memorandum Order 52 s. 2016. Pathways and Equity, Relevance and advancement in Research, Innovation, and Extension in the Philippine Higher Education. https://www.ched.edu.ph.

10. Cloete. N. Bailey T., \& Pillay, P. (2011). Universities and Economic development in Africa. African Minds. ISBN 978-1-920355-73-9.

11. Corpuz, D. (2010). Teaching Effectiveness and Training Needs Assessment among Tertiary Faculty of the Nueva Vizcaya State University. Unpublished Dissertation, Nueva Vizcaya State University, Bambang Campus, Bambang, Nueva Vizcaya.

12. Corpuz, D.A. (2020). Learning Management System to Enhance the Research Capability of Public School Teachers. International Journal of Advanced Trends in Computer Science and Engineering, 9, 127-131. https://doi.org/10.30534/ijatcse/2020/1991.22020

13. DepEd Order No.24 s. (2010). http://www.deped.gov.ph/orders/do-39-s-2016.

14. DepEd No 43. S. 2015. Adoption of the Basic Education Research Agenda. http://www.deped.gov.ph/ orders/do-39-s-2016

15. DepEd Order No. 39, s. 2016. Adoption of the Basic Education Research Agenda. http://www.deped.gov.ph/orders/do-39-s-2016

16. DepEd Order No. 16, s. 2017. Research Management Guidelines.

17. Ellis, N. \& Loughland, T. (2016). The challenges of practitioner research: A comparative study of Singapore and NSW. Australian Journal of Teacher Education. 41(2). https://doi.org/10.14221/ajte.2016v41n2.8

18. Enero, E.J. (2000). Towards the Nigerian University of the $21^{\text {st }}$ century: Challenges and Opportunities. Nigerian Administration and Beyond the year.

19. Ferrance, E., (2000). Action Research. Northeast and Islands Regional Educational Laboratory at Brown University, 1-33.

20. Fetalver, Jr. A. (2003). Predictors of Research Capability as to Research Management and Research Process of State Higher Education Institutions in Region IV, Philippines. Dissertation. Romblon State University.html.

21. Formeloza, R. \& Pateña, A. (2013). Research Capability of the Maritime Faculty Members and Senior Students in Lyceum International Maritime Academy. International Journal of Physical and Social Sciences vol3 (9). http://research.lpubatangas.edu.ph/wp-content/uploads/2014/05/IJMRA

22. Fuentes, H.C. (2017). Research Competency of Teacher Education Students in Eastern Samar State UniversityMain Campus. Cebu International Conference on Studies in Business, Management, Education, and Law. January 26.

23. Fullan, M. (2001). The New Meaning of Educational Change (3rd ed.). New York, NY: Teachers College Press. https://doi.org/10.4324/9780203986561

24. Hancock, D. R. (1995). What Teachers May Do to Influence Student Motivation: An ApplicatiL of Expectancy Theory? The Journal of General Education, 44(3), 170-179. cinapse.io/papers/177115625.

25. Hong, C.E. \& Lawrence S.A. (2011). Action Research in teacher education: Classroom inquiry, reflection, and data driven decision making. IJournal of Inquiry and Action in Education, 4(2). https://www.wpunj.edu/dotAsset/330733.pdf

26. Igwe, L.E. (2005). Instructional to Educational Administration. Port Harcourt. Global Link Communication International. 
27. Kutlay, N. (2012). A Survey of English Language teacher's views of research. Procedia-Social and Behavioural Science. 70, 188-206. https://doi.org/10.1016/j.sbspro.2013.01.055

28. Lacanaria, B.F. (2018). Faculty Research in Higher Education Institutions: Extent and hiding factors. https//dspace.slu.edu.ph./ha.ndle123456789/192

29. Lai, C.I. (1990). Comment on the Assessment of Engineering Education in Taiwan. In C.P.Chang(ed). The Development Tendency of the Taiwanese Higher Education in the Twenty-First Century-Structure, Function, and Organization, pp. 446-447. Taipei: National Normal University.

30. Lovat, T., Davies, M., \& Plotnikoff, R. (1995). Integrating Research Development in Teacher Education. Integrating Research Skills Development in Teacher Education. Australian Journal of Teacher Education, 20(1). https://doi.org/10.14221/ajte.1995v20n1.4

31. Manongsong, M.J. \& Panopio, P. (2018). Dentistry Faculty Members' Research Competencies and Attitude towards Research Engagement. Asia Pacific Journal of Education, Arts, and Sciences, 5(3) P-ISSN 2362-8022 E-ISSN 2362-8030. www.apjeas.apjmr.com.

32. McGill \& Settle (2012). Identifying effects of institutional resources and support on computing faculty research productivity, tenure and promotion,. International Journal of Doctoral Studies. 7, 167-198. https://doi.org/10.28945/1581

33. Morales, M.P. (2016). Participatory Action Research (PAR) cum actionresearch (AR) in teacher professional development: A literature review. International Journal of Research in Education and Science (IJRES), 2(1), 156-165. https://doi.org/10.21890/ijres.01395

34. Papanastaciou, E.C. (2005). Factor Structure of the attitudes toward research scale. Statistics Education Research Journal. 4(1), 16-26. Retrieved from https://www.stat.auckland.ac.nz/serj

35. Republic Act 9155. Governance of Basic Education Act of 2001.

36. Republic Act 10912. Continuing Professional Development Act of 2016.

37. Sagor, R. (2000). Guiding School Improvement with Action Research. Alexandria, VA: Association of Supervision and Curriculum Development. http://www.ascd.org/publications

38. Salom, M. D. (2013). Research Capability of the Faculty Members of DMMSU La Union Campus. International Scientific Research Journal. Vol. V(2) ISSN $2094-1749$.

39. Santo, A., Engstrom, M.E., Reetz, L., Schweinle, W. \& Reed, K. (2009). Faculty Productivity Berries and Supports at a School of Education. Innovative Higher Education, 34(2):117-129. https://doi.org/10.1007/s10755-009-9098-z

40. Stewart, T. (2013). Classroom Research and classroom teachers.FLLT Conference Proceedings. Language Institute Thammasat University. https://www.litu.tu.acth/journal/FLLTCP/proceedings/143.pdf

41. Tamban, V. E., \& Maningas, O. B. (2020). Research Capability of Public School Teachers: A Basis for Research Capability Enhancement Program. People: International Journal of Social Sciences, 6(1). pijss.2020.61.222235. https://doi.org/10.20319/pijss.2020.61.222235

42. Ulla, M.B., Barrera, K.I. \& Acompanado, M.M. (2017). Philippine Classroom Teachers as Researchers: Teachers' Perceptions, Motivations, and Challenges. Australian Journal of Teacher Education, Vol. 42(4). https://doi.org/10.14221/ajte.2017v42n11.4

43. Ulla, M.B. (2017). Teacher Training in Myanmar: Teacher's perceptions and implications. International Journal of Instruction. 10(2), 103-118. https://doi.org/10.12973/iji.2017.1027a

44. Vasquez, V.E. (2017). Teachers as Researchers: Advantages, disadvantages, and challenges for teachers intending to engage in research activities. Retrieved from https://www.academia.edu/

45. Vogrinc, J. \& Zuljan, M. Action Research in schools-an important factor in teachers' professional development. (2009). Educational Studies vol 5(1), 53-63. https://doi.org/10.1080/03055690802470399

46. Wichian, S. Wongwanich, S. Bowarnkitiwong, S. (2009). Factors Affecting Research Productivity of Faculty Members in Government Universities: Lisrel and Neural Network Analyses. Kasetsart Journal - Social Sciences 30(1).

47. Wodarski, J. S. (2001). Promoting Research Productivity among University Faculty: An Evaluation. Research on Social Work Practice. 1: 278-288. https://doi.org/10.1177/104973159100100304

48. Wong, M. (2019). Driving Forces of Master Teachers' Research Capability: Towards Building A Research Culture In The Division Of Romblon, Philippines. International Journal of Advanced Research and Publications, Vol. 3, Issue 7. http://www.ijarp.org/published-research-papers/july2019

49. Sheikh, A.S., Sheikh, S.A., Kaleem, A., \& Waqas, A. (2013). Factors contributing to a lack of interest in research among medical students. Advances in Medical Education and Practice. 4:237-43. https://doi.org/10.2147/AMEP.S51536

50. Zhou, J. (2012). Problems teachers face when doing action research and finding possible solutions: Three cases. Chinese Education and Society. 45(4), p68-80. https://doi.org/10.2753/CED1061-1932450405

51. Yuan, R. \& Lee, I. (2014). Understanding language teacher educators' professional experiences: an exploratory study in Hongkong. Asia Pacific Education Researcher v23, pp143-149. https://doi.org/10.1007/s40299-0130117-6

52. Zulueta, F.M., and Perez, J.R. (2010). Methods of Research: Thesis Writing and Applied Statistics. Manila: National Book Store. 